\title{
Concepções de boa postura dos participantes da Escola Postural da ESEF/UFRGS
}

*Adriane Vieira

**Jorge Luiz de Souza

\section{Resumo}

Neste artigo apresentamos e discutimos concepções de boa postura engendradas na dissertação de Mestrado "A Corporeidade na Escola Postural". As reflexões são realizadas a partir de entrevista semi-estruturada realizada com dez participantes inscritos no programa de extensão Escola Postural oferecido à comunidade na EsEF/UFRGS em 1997. A análise das entrevistas possibilitou-nos compreender que a concepção de boa postura dos participantes é bastante semelhante à difundida na literatura a partir do século XIX, a qual prioriza o alinhamento e posicionamento dos segmentos corporais, a força e tensão muscular e o controle e disciplina corporal. Concepções mais atuais relacionadas à percepção corporal são pouco citadas pelos entrevistados.

D escritores: Postura corporal, Escola Postural

\footnotetext{
Abstract

In thisarticle, we present and discuss conceptions of good posture engendered in the master thesis titled "Corpority in Back School". The reflections are done based on a semistructured interview applied to ten participants inscribed in theextensionprogram Back School offered to the general community at ESEF/ UFRGS, in 1997. The analysis of the interviews allowed us to comprehend that the participants' conception of good posture is very similar to that disseminated in literature from XIX century on, which gives priority to the alignment and position of body segments, to muscular strength and strain, and to body control and discipline.
}

More recent conceptions related to body perception are little men tioned by the subjects in terviewed.

Keywords: Bodyposition, school

\section{Introdução}

A boa postura é considerada fator importante à saúde do sistema músculo-esquelético, pois se acredita que ela possa evitar problemas álgicos e processos degenerativos. Assim, propostas educativas, preventivas e terapêuticas têm sido oferecidas à população com o objetivo de oportunizar uma melhora da postura corporal, por exemplo, a Escola Postural. Entretanto,
intervir na postura de disso, na uma pessoa significa, atualidade, há num certo sentido, muitas indicar-lhe maneiras de controvérsias entender-se e de sobre o que é uma comportar-se corporalmente. Por isso, boapostura e o corporalmente. Por isso, $q u e$
prescrever uma boa postura não é um devemos fazer assunto tão simples quantolpara obtê-la. de início possa parecer. Além disso, na atualidade, há muitas controvérsias sobre o que é uma boa postura e o que devemos fazer para obtê-la.

Segundo Vigarello (1978), no transcorrer da história ocidental, a boa postura tem sido entendida como perfeito alinhamento dos segmentos corporais. Associada ao discurso moral na Idade Média, a postura associou-se ao discurso de saúde física no século 
XVI, o que justificou o início de intervenções diretas sobre a postura como um dos recursos para promoção da saúde.

No século XIX, momento em que o corpo era compreendido como uma máquina capaz de produzir trabalho, começa a ser recomendado a toda população exercícios corretivos, priorizando a força e a disciplina corporal, os quais visavam garantir a boa postura, em outras palavras, a retitude corporal; medida condizente e inserida no projeto higienista e industrial da época.

No século XX, esta concepção de boa postura permaneceu predominante, apesar do redimensionamento do corpo propiciado por várias áreas de conhecimento e do surgimento e difusão de novas concepções. A noção de esquema e imagem corporal advinda da neurologia e da psicologia, desenvolvidas principalmente por Schilder (1994), foi uma das teorias que fortemente influenciaram, principalmente entre as décadas de 60 e 80, as concepções sobre a postura. Nesse período, vários autores, entre eles Feldenkrais (1977), Hanna (1988), Lapierre (1982) eSmith, Weiss e Lehmkuhl (1997), questionaram a visão mecânica e retificada da boa postura e salientaram o caráter individual e comportamental da postura humana. Esses autores, continuaram defendendo a postura como uma questão de saúde, mas eles não mais a associaram à exercícios corretivos para reforço de ações musculares isoladas, e sim ao conhecimento e percepção do corpo, ao estado tônico dos músculos e aos hábitos posturais, possibilitando o surgimento de novas categorias para se pensar e abordar a postura corporal. Poderíamos dizer que esses autores propõem que a intervenção mecânica sobre postura seja substituída por uma intervenção sensório-motora; concepção recente em termos históricos e, portanto, pouco conhecidas.

Como profissionais que atuam na educação postural, preocupamo-nos em refletir como essas diferentes concepções de boa postura são incorporadas pelas pessoas, ou seja, como elas a entendem e quais recursos utilizam para obtê-la. Portanto, nosso objetivo nessa investigação é, a partir da fala dos entrevista- dos, compreender e discutir como as concepções de boa postura, propostas pelos especialistas e mencionadas acima, estão presentes no discurso das pessoas que procuram a Escola Postural.

\section{Metodologia}

As falas apresentadas nesse artigo foram obtidas através de entrevistas semi-estruturadas realizadas com 10 voluntários (nove mulheres e um homem, com idades entre 34 a 57 anos), inscritos no programa de Escola Postural oferecido no segundo semestre de 1997 na EsEF/UFRGS. As entrevistas foram gravadas em fita cassete e, após a transcrição, foram agrupadas em unidades de significado para compor a descrição e discussão apresentada neste artigo (Metzler, Carpena \& Borges, 1994). Procedimentos apropriados foram adotados para obtenção do consentimento de participação no estudo. Os nomes utilizados são fictícios, preservando a identidade dos participantes.

\section{Descrição e discussão}

Uma das questões norteadoras no transcorrer da entrevista realizada com os participantes inscritos no programa de Escola Postural foi: "O que é uma boa postura para você?". De acordo com as respostas, outras questões foram sendo formuladas, a fim de melhor compreender as concepções de boa postura dos entrevistados. A concepção central nas definições e nos argumentos apresentados pelo entrevistados demonstrou que, de diferentes maneiras, eles parecem entender a boa postura como o perfeito alinhamento dos segmentos corporais. Algumas falas relacionaram diretamente boa postura e alinhamento corporal:

Célia: "Eu acho que boa postura é a coluna estar bem centralizada, principalmente a coluna. Eu acho que ela tem de estar bem retinha, bem direitinha." 
Flávia: "Ter boa postura é você estar com o corpo bem retinho, bonitinho."

Helga: "Para ter boa postura acho que tem de começar lá debaixo, com as pernas, os pés, encaixe de quadril, os ombros no lugar, o peito, a cabeça alinhada. O peito deve ser com o esterno para fora, em equilíbrio com os ombros e a cabeça, se sentir no prumo, numa linha reta."

Joana: "Uma postura no equilíbrio, no eixo, na vertical mesmo. "

"Eu consigo o estado ideal poucas vezes, mas é muito bom, é um estado de equilíbrio mesmo, vertical."

Mas, os entrevistados também demonstraram a idealização da retitude corporal, como referência de boa postura, de maneira indireta quando citarem insatisfações em relação as suas posturas:

Berta: "Eu não estou conseguindo me [...] [fez um gesto de extensão da coluna] e a parte de cima quer ir [...] [fez gesto de flexão da coluna]. Ainda mais que eu tenho bastante seio, né? Pesa.Estou ficando com os ombros caídos."

Célia: "Eu acho queeu tenho os ombros muito pesados. Eu acho que eu tenho os ombros muito caídos, que eu me atiro muito para frente e porque eu sinto dor aqui."

Edla: "Quando eu percebo que meu tronco está mais para frente, já está me cansando de manter aquela posição, começo a sen tir dor nas costas. Ai é que eu me dou conta, com a dor, eu me dou conta da postura. Ai eu corrijo fisicamente a postura e vejo o quanto eu estava para frente."

Flávia: "Eu noto, até caminhando na rua eu noto, não, eu sinto ou olho num espelho que minha postura aqui em cima, nos ombros [...] eu noto muito."

Ida: "O que eu acho bonito é aquele tipo ideal, que não é para mim, que não é o meu tipo físico, que é aquela pessoa que tem as costas retinhas, que eu vejo que também tem problemas de coluna, aquilo eu acho bonito [...] eu sei que nunca vou ter e não me incomoda mais. E muito de aceitação pessoal."

"As vezes, mesmo que eu tente ficar com as costas retas, eu vejo que ainda tem esse S."

As expressões bem retinha, uma postura na vertical mesmo, no prumo aproximam-se do protótipo da boa postura ou de postura ideal apresentada por alguns autores (Bowen, 1953; Sousa, 1972; Knoplich, 1985; Kendall, McCreary e Provance, 1995). E, o aumento da cifose dorsal e os Portanto, cabe que foram salientados eperguntar: associados à dor, à derrota, qual o objetivo à perda da estatura e à fei-de um modelo úra pelos entrevistados depostura são citados por esses ideal (posturaautores como sinal de má $\mid$ padrão), se ele

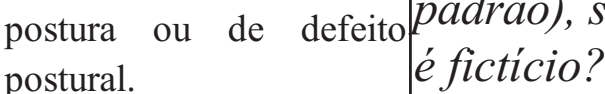

Kendall, McCreary e Provance (1995), considerados uma das principais fontes bibliográficas sobre postura, avaliam o alinhamento corporal no teste de fio de prumo, tendo como parâmetro uma postura-padão. Esses autores afirmam que os desvios da postura-padrão são defeitos, mas, na mesma página, afirmam que não se espera que alguém consiga combinar o padrão em cada aspecto e que jamais viram alguém que o fizesse. Portanto, cabe perguntar: qual o objetivo de um modelo de postura ideal (postura-padrão), se ele é fictício? será possível que a mesma postura seja a ideal para todas as pessoas? Se os desvios da postura-padrão são defeitos, mas dificilmente há alguém que consiga corresponder a essa atitude corporal, poder-se-ia inferir que não existem pessoas perfeitas, ou questionar se a retitude corporal é uma referência ade- 
quada para se pensar e se avaliar a qualidade da postura.

Outro fato relevante é que Berta, Célia e Flávia não apresentavam ombros caídos e um aumento da cifose dorsal, ao contrário do que imaginaríamos a partir de suas falas, fazendo-nos questionar o que as levou a ter essa imagem de si. Uma possibilidade seria justamente a busca da perfeição, a qual nos leva a freqüentes insatisfações. Os padrões de retitude, os quais são também estéticos, são rigorosos e sempre interferem na imagem que temos de nosso corpo, e, ao que parece, a cifose e os ombros caídos são os "defeitos" mais temidos, considerados os que mais denigrem a postura corporal. Dificilmente chama-se a atenção de alguém por estar com as

costas retas demais, o que biomecanicamente seria Colocar o corpotão desfavorável ao no lugar, manter uma organismo quanto o aumento postura bem retinha $\left.\right|_{\text {das }}$ curvas verte-brais. muitas vezes Kapandji,(1990),aco-luna relaciona-se a uma torna-se mais resistente às contração pressões mecânicas quando muscular voluntária apresenta curvas, e talvez e prejudicial. seja mais prejudicial a diminuição dessas do que seu aumento. Porém, a idéia de uma coluna reta é culturalmente almejada, enquanto que o aumento, principalmente o da cifose dorsal, é visto como problema, mesmo quando ele é bastante sutil.

Outra concepção associada a retitude corporal, citada pelos participantes, foi a necessidade de colocar no lugar certo ou encaixar os segmentos corporais:

Ana: "Eu sempre leio muito sobre postura, tento botar no lugar a pélvis, as costas, os ombros."

Flávia: " Tenho uma esperança de colocara minha postura no lugar."

"Para sentar, eu só cuido os ombros para manter no lugar."
"Eu sentava retinha, sempre puxando a barriga, encaixando o quadril, tinha todos esses cuidados, depois que eu engordei não fiz mais nada disso."

Joana: "Uma coisa encaixada em cima da outra no corpo, às vezes eu consigo sentir isso, mas é dificil, não é muito comum."

Colocamos nossos pertences, tais como bibelôs, eletrodomésticos, livros, em lugares estipulados, dobramos e empilhamos nossas roupas no armário, encaixamos tampas em potes plásticos. Mas o que significa encaixar ou colocar o corpo no lugar? Como fazemos para colocar nosso corpo no lugar? Será que existe um encaixe certo para cada segmento corporal? Ter boa postura significa enquadrarmo-nos a um modelo? Encaixar o corpo proporciona bem-estar? Devemos ter sempre a mesma postura ou as variações são importantes?

Colocar o corpo no lugar, manter uma postura bem retinha muitas vezes relaciona-se a uma contração muscular voluntária e prejudicial. Se alguém tem uma postura $x$, e procura posicionar-se como vou como um ideal proposto por manuais de postura, terá de manter em contração determinados músculos para poder copiá-la. Segundo Smith, Weiss e Lehmkuhl (1997), a postura deveria ser entendida como uma maneira característica de cada indivíduo sustentar seu corpo. Esses autores sugerem que a postura idealmente vertical, denominada por eles perpendicular, não é natural (sendo necessário solicitála), exigindo esforço consciente e aumento marcado da atividade muscular, se comparada com a postura ereta relaxada. Defendem, assim, que o parâmetro de uma postura ereta normal deve ser o relaxamento e o conforto corporal, ao invés de um modelo idealt pré-determinado de alinhamento corporal. Para eles, esse referencial surge de um engano na leitura do artigo de Braune e Fischer publicado em 1889.

Feldenkrais (1977) também aborda a questão de excesso de tensão muscular associado a certas prescrições de boa postura no livro Consciência pelo Movi- 
mento, quando fala do corriqueiro comando "sente direito"dado, principalmente, às crianças. $\mathrm{O}$ autor alega que esse comando é enganoso porque "não expressa o que queremos conseguir ou ver depois que o aperfeiçoamento tiver acontecido" (p.92). Além disso, afirma que, muitas vezes, nem mesmo a pessoa que solicita à outra que sente ou fique "direito" sabe exatamente o que quer dizer com "direito" e nem o que é necessário para se assumir tal postura. Quando se solicita a alguém que "sente direito ", estáse sugerindo que algo está errado na sua postura; então a pessoa deve fazer alguma coisa diferente do que estava fazendo, mas o quê? E provável que a reação seja contrair os músculos das costas e elevar o peito, ou seja, enrijecer o corpo. Será que isso resolve? Dificilmente. O excesso de contração muscular será percebido, solicitando o relaxamento da musculatura, ou a pessoa retomará sua postura habitual quando se distrair. Entretanto, se a pessoa considerar a correção necessária, ou se ela for solicitada várias vezes, poderá incorporá-la à sua postura, e a tensão muscular decorrente da correção tornar-se-á habitual e não mais será percebida, isto é, terá internalizado um novo hábito postural. Talvez, para "sentar direito", o mais indicado seja modificar o posicionamento da pélvis de maneira que as curvas vertebrais sejam mantidas, solicitando apenas contrações reflexas da musculatura paravertebral; mas dificilmente lembramos ou sabemos da importância do posicionamento da pélvis para mudar a atitude postural da coluna, e associamos o "fazer direito" à mera contração da musculatura das costas e do abdômen. Quando sentamos com a pélvis em retroversão, a coluna lombar posiciona-se em cifose; isso leva a um arredondamento de toda a coluna, que pode ser compensado a nível cervical (aumentando-se a lordose cervical) a fim de manter o olhar num plano horizontal. Se tentarmos "sentar direito" sem saber sobre a organização da nossa coluna, é possível que ao invés de modificar a posição da pélvis façamos um esforço para retificar a cifose dorsal. Tanto a contração da musculatura paravertebral para retificar a região dorsal da coluna, como a mudança no posicionamento da pélvis, darão uma aparência de Verticalidade do tronco, mas, no primeiro caso, a coluna é posicionada na vertical por um maior esforço da musculatura paravertebral, enquanto que, no segundo, a coluna se posiciona na sua funcionalidade, que se caracteriza pela manutenção das curvas fisiológicas e por uma ação muscular reflexa. Assim, as solicitações de endireitamento da postura acabam estimulando as tensões musculares ao invés de facilitar a funcionalidade inscrita em nossa anatomia. Berta refere-se a isso quando diz: "acho que ter boa postura é caminhar, sentar ereta, sem fazer força, porque eu tenho que fazer força". Assim, considera que só tem boa postura quando faz força, apesar de achar que isso não é adequado. Flávia também explicita a idéia de força associada à boa postura ao dizer que: " $a$ professora de ginástica usava muito encaixar o quadril. Então botava no lugar, mesmo que fosse com força, como eu te disse, mas se botava, se encaixava, tentava todo tempo ficar com o quadril encaixado, mesmo nos exercícios, era fundamental na época."

Flávia aprendeu que para ter boa postura deve encaixar os segmentos corporais através da força muscular, considerando-a necessária e válida. Na literatura, encontramos alguns autores que também consideram a força e o endurecimento muscular necessários à boa postura. Rasch e Burke (1977), por exemplo, dizem que uma das principais causas da má postura são as fraquezas musculares, e, por isso:

\footnotetext{
"os ossos, os tendões e os músculos devem ser fortalecidos e endurecidos através de esforços e resistência, gradualmente progressivos, de modo que elas possam confrontar, adequadamente, com as forças comuns encontradas na vida cotidiana." (p.439)
}

No livro Viva Bem com a Coluna que Você Tem, o autor Knoplich (1996), ao falar sobre a maneira correta de caminhar, diz: 
"O método correto de andar é olhando sempre para a linha do horizonte, olhando as pessoas nos olhos e até mesmo com um certo ar de arrogância. Isso significa que a cabeça está erguida e não apenas os ombros. O caminhar de cabeça baixa dá um certo ar de timidez, insegurança. Ao caminhar, contraia a musculatura abdominal e as nádegas." (p.139)

Contrair a musculatura do abdômen e das nádegas leva-nos ao encaixe pélvico, e erguer os ombros, ao encaixe dos ombros, atitudes que são comentadas pela participante Flávia. Cabe, porém, questionar: como é possível, durante o caminhar, manter a mobilidade flexo-extensora da articulação do quadril, se a contração dos glúteos mantém uma força extensora? para que serve erguer os ombros? qual o benefício dessas contrações? será que a contração ininterrupta das nádegas, do abdômen e dos ombros não limita a mobilidade articular requerida às atividades de vida diária?

Exercícios de retroversão pélvica e solicitações de encaixe do quadril na posição ortostática surgiram a partir de um referencial teórico que considera a hiperlordose a causa das dores lombares (Calliet, 1987; Knoplich, 1996). A utilização de tal atitude postural como meio preventivo ou terapêutico difundiu-se e tornou-se um procedimento adotado indiscriminadamente pelos profissionais de Educação Física e Fisioterapia, um pré-requisito em quase todas práticas corporais. Entretanto, poucos questionam se essa é uma medida adequada ou não. A queixa de dor pode ter outras causas, e, conforme a estrutura corporal do indivíduo, esses exercícios padronizados podem, se não piorar sua dor, piorar sua atitude postural. Ademais, a retroversão pélvica é também solicitada em aulas de ginástica, alongamento, etc, àqueles que não apresentam hiperlordose e nem queixa de dores lombares. Por isso, é necessário um olhar crítico acerca da sua utilização.

Outro problema que podemos levantar em relação às idéias de colocar o corpo no lugar certo e manter a coluna bem retínha, é que elas indicam uma imobilidade corporal, uma manutenção estática e sempre igual da postura, o que se opõe a um corpo flexível, dinâmico e disponível para o movimento. Uma postura estática sustentada por longo período possivelmente solicitará a contração contínua e excessiva de determinados músculos, o que pode desencadear processos álgicos, dificuldade à circulação sangüínea, compressão articular e lesão muscular.

LeCamus (1986) e Müller (1994), reconhecendo no problema da tensão muscular um dos motivos de queixas e problemas para muitas pessoas, sugerem exercícios de relaxamento. Na maioria desses exercícios, a pessoa deita-se no chão, fica em silêncio e imóvel, procurando diminuir a atividade muscular, o que a ajuda a perceber as tensões presentes no corpo e, às vezes, mesmo sem perceber, a soltá-las (Souza, 1995). Mas será que não devemos estar relaxados também durante o movimento? Será que não podemos ter uma boa postura e ao mesmo tempo estarmos relaxados? Para relato de alguns participantes, parece que não:

Ana: "Eu tento melhorar a postura, mas, se eu relaxo, já volta, tenho que estar sempre controlando."

Célia: "Eu acho que tem de se reeducar para ter uma postura; eu, pelo menos, não tenho mais, o dia a dia vai levando a gente para um relaxamento.

Flávia: "...eu sinto ou olho num espelho que minha postura aqui em cima, nos ombros... eu noto muito, então tento corrigir; toda vez que eu me dou conta que en estou jogada, eu ponho meu corpo no lugar. Aposição que eu estou sentada agora, eu estou totalmente relaxada aqui [passou a mão no abdômen], o que não é correto."

Helga: "A minha postura é aquilo que, quando eu estou muito cansada, eu relaxo conscientemente, mas normalmente eu procuro manter a postura, às vezes eu me pego assim, meio relaxada, meio desencaixada." 
"Agente também acaba, sempre relaxando na postura, então ébom ficar revendo."

No dicionário (Ferreira, 1999), encontramos várias acepções para o verbo relaxar, dentre elas: [1] diminuir a força ou a tensão de; tornar frouxo ou lasso; afrouxar; [2] dispensar do cumprimento de (lei ou dever); [3] Corromper, perverter, depravar; [4] Tornar-se negligente, desleixar-se, desmazelar-se; [5] Desmoralizar-se, perverter-se, corromper-se. Os direrentes significados presentes nessas definições nos levam a associar o relaxamento, isto é, a diminuição da tensão muscular nas posturas do cotidiano, a valores simbólicos de fraqueza, de não-cumprimento dos deveres, de desmoralização e de perversão. A boa postura é, então, incompatível com um estado de relaxamento muscular, o qual levaria simbolicamente ao desleixo, à perda de uma atitude corporal socialmente e moralmente adequada. Como coloca Ana: "umapessoa que é muito caída, eu tenho a impressão que ela é mais relaxada, não sei, mais desligada, né? Se ela larga o corpo, não sei... Eu estou sempre naquela postura [extensão da coluna] e prestando atenção nas coisas."

Nessa afirmação, Ana sugere que, para ter boa postura, é necessário manter o corpo atento ao cumprimento das leis e deveres, o que nos remete a postura militar reconhecida culturalmente como protótipo da boa postura. Exige-se do militar, desde o século XVIII, uma disciplina corporal rigorosa e uma postura característica, tal como descreve o autor Foucault (1996) em seu livro Vigiar e Punir.

"Os recrutas são habituados a manter a cabeça ereta e alta; à se manter direito sem curvar as costas, a fazer avançar o ventre, a salientar o peito, a encolher o dorso; e a fim de que se habituem, essa posição lhes será dada apoiando-os contra um muro de maneira que os calcanhares, a batata da perna, os ombros e a cintura encostem nele, assim como as costas das mãos, virando os braços para fora, sem afastá-los do corpo [...] ser-lhes-á, igualmente ensinado a nunca fixar os olhos na terra, mas a olhar com ousadia aqueles diante de quem eles passam [...] a ficar imóveis esperando o comando [...]" (p. 125)

Segundo Foucault, até o século XVII os soldados eram selecionados pelas suas aptidões físicas, pelo seu porte e postura, mas, a partir da segunda metade do século XVIII, eles passaram a ser:

\begin{abstract}
" [...] algo que se fabrica; de uma massa informe, de um corpo inapto, fez-se a máquina de que se precisa; corrigiram-se aos poucos as posturas; lentamente uma coação calculada percorre cada parte do corpo, se assenhoreia dele, dobra o conjunto, torna-o perpetuamente disponível, e se prolonga, em silêncio, no automatismo dos hábitos; em resumo, foi 'expulso o camponês' e the foi dado a 'fisionomia de soldado'."(p.125)
\end{abstract}

Observamos que os comentários de alguns participantes sobre "boa postura" são condizentes com a postura militar, mostrando-nos o quanto à concepção de uma postura corporal rígida e retificada ainda é valorizada socialmente. Isso condiz, em certa medida, com a expressão "policiar o corpo" utilizada por Berta e Célia na entrevista. Para elas, "policiar o corpo" significa controlar as atitudes posturais que assumem nas atividades de vida diária e, é provável, que a escolha desta expressão e não de outras para se referir as suas posturas tenha um significado.

Por outro lado, Flávia e Helga acabam dizendo que se permitem, na intimidade, um relaxamento, mesmo que por pouco tempo:

Flávia: "Adoro me deitar no sofá de qualquer jeito, com as pernas para um lado, o corpo para o

\section{5}


outro, com as pernas penduradas de qualquer jeito, ali eu tiro o meu cochilo. Bem torta, eu sei que é bem torta, uma postura que não tem nada a ver."

Helga: "Quando eu estou muito cansada, ai eu me jogo mesmo, aí eu sei, é consciente mesmo: 'eu não deveria estar sentada assim, mas está tão bom'; bem relaxada mesmo."

Nessas colocações observamos que a satisfação em relaxar, em posicionar-se de qualquer maneira, é acompanhada pela sensação de estar fazendo algo errado. Há, portanto, uma cobrança pessoal em manter o corpo bem posicionado, o que poderíamos denominar de um corpo bem disciplinado, e, ao mesmo tempo, uma satisfação, um prazer, na quebra dessas cobranças, na liberdade para perder a compostura. A disciplina corporal citada como uma cobrança pessoal por duas das participantes, foi citada como uma cobrança social pela maioria dos entrevistados:

\section{[1] na infância:}

Diana: "pára direito, tu tá torta"; "te ajeita"; "te endireita"; "olha o teu caminhar"

"toma cuidado, tu tem tendência a ficar que nem o tio; olha a mãe, como ela já está".

Helga: "olha as costas"

"vamos sentar mais reto um pouquinho"

"'ah, vai ter de usar colete, vamos lá, vamos fazer exercício', meio que na imposição."

Ida: "espicha as costas."

\section{[2] na vida adulta:}

Diana: "não tenha vergonha, abra os ombros"; "abra os ombros."
Edla: "tu, tão jovem, com essa postura tão

fechada." "te endireita, melhora a posição."

\section{[3] e na atualidade:}

Berta: "olha, mãe, tu estás curvada, olha as costas, mãe"

Diana: "Só tens barriga porque tu não sabe te posicionar, porque, se tu te colocares de maneira correta, tu não é barriguda", "de repente é só postura, vai ver isso aí".

"Quando as pessoas me vêem, dizem que eu tenho uma curva bastante acentuada aqui nas costas [lombar]."

Flávia: "Minha filha, que está todo dia comigo, me chama a atenção da minha postura diariamente."

Gérson: "Quando fiz um curso, eu estava com escoliose, com um pouco de escoliose, também a questão postura!."

"Outra vez falaram sobre um problema pélvico, de como minha pélvis é rodada para frente."

Ida: "Alguém entrou e comentou com a minha colega de como a datilografia castiga as pessoas; aí, quando ele falou, eu me dei conta de como eu estava completamente torta, um perfeito corcundade NotreDame."

Como vemos, quando a postura foge dos moldes aceitos como adequados pela sociedade, as outras pessoas começam a cobrar do indivíduo uma mudança na sua atitude postural, solicitam que a pessoa se corrija ou procure uma ajuda para isso. Então é difícil saber se o interesse em modificar-se é próprio do indivíduo ou uma resposta às cobranças alheias. Diana diz: "tenho I lembranças terríveis, os apelidos que eu ganhava ". Ela I era mais alta do que seus colegas e muito magra, e diz que:" talvez até em Rincão da altura que a gente vai se encolhendo ". Edla também se ressentiu com as cobranças que recebia: "eu me lembro que eu era jovem, tinha

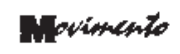

Movimento, Porto Alegre,

V. 8 , 1, p. $9-20$, ja n e i ro/a b r i l 
uns 20 anos e todo mundo falava 'te endireita', 'melhora aposição', e eu tinha um constrangimento de ficar sempre curvada para frente ". Berta e Flávia verbalizaram que, desde a adolescência, foi-lhes ensinado andar de salto alto e manter as pernas fechadas ao sentar. Helga associa as cobranças familiares acerca da sua postura a uma questão cultural:

Helga: "familia de alemão foi sempre assim, todo mundo tem de sentar reto, direitinho na cadeira (...) Meu pai conta que ele também tinha tendência a sen tar torto, que os pais dele sempre chamavam a atenção (...) mas também é bem cultural."

E ela demonstra dar continuidade a esse controle da postura, considerando necessário manter-se direito:

Helga: "Eu incentivo meus filhos a sentarem direitinho."

"Eu vejo que o meu filho está curvado, eu falo, mostro no espelho, a forma que ele senta no sofá, eu tento explicar, mas ele está seguindo aquela minha tendência."

A retitude é culturalmente cobrada porque denota bom caráter, concepção, às vezes, reforçada em livros redigidos por especialistas. Knoplich (1996), por exemplo, ao falar do "método correto" de caminhar, diz que devemos olhar as pessoas com certo ar de arrogância e não baixar a cabeça, o que representaria timidez e insegurança. Sousa (1972) diz que o indivíduo que tem boa postura "verá a vida de um ponto de vista otimista, ganhará o respeito de seus concidadãos e será um membro útil á sociedade" (p.50). Esses autores reforçam opiniões culturais da relação entre o bom caráter e a boa postura corporal; os indivíduos que não se enquadram nesse modelo são, por conseguinte, estigmatizados.
As classificações simplistas das relações entre postura e caráter reforçam a padronização de posturas socialmente vantajosas, não só levando as pessoas a almejá-las com fins de serem bem vistas e aceitas na sociedade, mas também gerando incômodo a quem não consegue corresponder a esse modelo. As supra-citadas palavras da participante Ida, que demonstram sua insatisfação por não apresentar o tipo físico ideal, atestam esse fato.

A partir do século XVI, definir parâmetros para a boa postura passou a ser responsabilidade da Medicina e áreas afins; esperando-se que os estudos dos especialistas determinassem o correto e adequado para a saúde e o bem-estar do ser humano. Porém, ainda encontramos livros cujas fotografias, desenhos e descrições a respeito da boa postura (Kelly, 1949; Bowen, 1953; Kendall,McCreaiy\&Provance, 1995; Knoplich, 1996) fazem lembrar a "fisionomia de soldado" idealizada no século XVIII descrita em Vigiar e Punir de Foucault (1996): das costas sem curvas, do peito saliente, do ventre contraído, dos ombros puxados para trás. Muitos autores ainda sugerem que essa "boa postura", tal como no século XIX, deve ser alcançada através de exercícios corretivos, de treino da força muscular e de automatização.

Nas entrevistas realizadas, a concepção de boa postura associada a uma questão de mobilidade e relaxamento muscular difundida nos últimas décadas foi citada apenas por dois participantes:

Diana: "Boa postura é você não forçar o corpo, você estar numa posição que não está exigindo do corpo mais do que ele pode te dar, você estar sentado duma maneira que você não está forçando nada, que está de acordo com a musculatura (...) conhecer mais o corpo para saber onde você distribui, onde está seu equilibrio."

Gérson: "Eu acho que é se sentir numa postura relaxada, alguma coisa assim, teu corpo todo."

Essas colocações salientam o bem-estar, o relaxamento, o que é natural, o conhecer o corpo, dando outra 
dimensão às concepções sobre a postura corporal vistas até aqui e estão relacionadas à segunda concepção apresentada na introdução deste artigo. Não se trata de encaixar, corrigir ou controlar o corpo para formatá-lo ao modelo ideal de postura, mas de conhecer-se e perceber-se melhor, de encontrar caminhos que favoreçam o bem-estar, os quais são peculiares a cada indivíduo. São conhecimentos que devem ser ensinados através de propostas que valorizem a experiência sensório-motora e que devem aumentar o entendimento que o aprendiz tem dos seus próprios movimentos. Autores que trabalham nessa perspectiva, como Feldenkrais (1977), Lapierre (1982), Hanna (1988), Alexander (1992), DenysStruyf (1995), valorizam a reconstrução da imagem corporal do indivíduo, isto é, pretendem que ele se compreenda melhor, identificando suas dificuldades e necessidades a partir de certas propostas vivências e da atenção dada as suas percepções. Esperam que, experimentando o corpo próprio, o indivíduo se questione e aprenda sobre si mesmo, sendo a função do professor orientar e facilitar suas descobertas. Os conhecimentos advindos da Anatomia, Fisiologia, Biomecânica e Cinesiologia são utilizados para informar, para enriquecer discussões, para auxiliar na compreensão do corpo próprio, e não para impor, do exterior, o que é correto e ideal. Mas, como podemos observar essa concepção se mostrou secundária ou desconhecida pelos entrevistados, possivelmente por ser uma concepção muito nova em comparação a concepção anterior de boa postura, a qual vem sendo difundida a mais de um século, e por estar relacionada a um outro entendimento do corpo humano, o qual está longe de ser dominante na nossa sociedade e na nossa cultura.

\section{Considerações finais}

As entrevistas realizadas com participantes da Escola Postural da EsEF/UFRGS nos possibilitaram compreender as concepções daqueles que estão buscando um caminho para melhorar sua postura e discutilas a partir do que é apresentado na literatura e das nossas concepções como profissionais que trabalham com a educação postural. Podemos constatar que, apesar das divergências encontradas atualmente na literatura, as concepções de boa postura que predominaram na fala dos participantes estão vinculadas a concepções que se difundiram amplamente no século XIX e permaneceram dominantes no século XX. Concepções desenvolvidas e difundidas nas ultimas décadas, discordantes da relação entre boa postura e retitude corporal, manutenção da postura pela força muscular e a disciplina corporal, as quais possibilitariam um outro entendimento da postura corporal, foram pouco comentadas. Isso mostra que tais concepções são pouco conhecidas e incorporadas entre aqueles que se interessam em ter uma boa postura.

No transcorrer da discussão, buscamos questionar as concepções dos participantes sobre a boa postura e demonstrar que elas são formuladas, principalmente, a partir de argumentos associados a valores simbólicos, morais e estéticos vislumbrados na idealização de um corpo reto que não se entrega ao relaxamento e é colocado no lugar certo, mesmo que seja com força. As cobranças sociais e pessoais sobre a manutenção de um determinado contorno corporal e a relação entre boa postura e bom caráter, comentadas pelos participantes, também nos possibilitam compreender que as concepções de boa postura não se restringem a um discurso embasado em questões orgânicas e biomecânicas para promoção da saúde física. E interessante perceber valores morais entremeados também em livros redigidos por especialistas, fazendo-nos considerar que o "discurso científico sobre a boa postura" ainda está ligado a concepções sociais e culturais advindos da Idade Media e reproduzidas através dos séculos.

Para finalizar, gostaríamos de ressaltar nossa preocupação de um maior entendimento do que tem 
sido dito e proposto em relação à postura corporal e da necessidade de um maior cuidado com os discursos e as práticas corporais que estamos ajudando a perpetuar ou a renovar. Entendemos que, ao intervir sobre a postura corporal e ao prescrever o que é bom ou ruim à saúde, estamos influenciando a maneira das pessoas pensarem-se e comportaremse corporalmente, estamos, portanto, interferindo na construção e na compreensão de seus complexos corpos humanos.

\section{Referências Bibliográficas:}

ALEXANDER, F.M. O Uso de Si Mesmo. São Paulo: Martins Fontes, 1992.

BOWEN, W.P. Applied Anatomy and Kinesiology: The Mechanism of Muscular Movement. 7ed., Philadelphia: Lea \& Febiger, 1953.

CALliEt, R. Compreenda sua Dor de Coluna. São Paulo: Manole, 1987.

DENYS-STRUYF, G. Cadeias Musculares e Articulares: O Método G.D.S. São Paulo: Summus, 1995.

FELDENKRAIS, M. Consciência pelo Movimento. São Paulo: Summus, 1977.

FOUCAULT, M. Vigiar e Punir: História da Violência nas Prisões. I4ed., Petrópolis: Vozes, 1987.

FERREIRA, A.B.H. Novo Aurélio Século XXI: o Dicionário da Língua Portuguesa. 3ed., Rio de Janeiro: Nova Fronteira, 1999.

HANNA, T. Somatics: Reawakening the Mind's Control of Movement, Flexibility, and Health. Massachusetts: Addison-Wesley, 1988.

KAPANDJI, LA. Fisiologia Articular: Esquemas Comentados de Mecânica Humana. 5 ed., São Paulo: Manole, 1990.

KELLY, E.D. Teaching Posture and Body Mechanics. New York: Barnes and Company, 1949.

KENDALL, F.P.; McCREARY, E.K.; PROVANCE, P.G. Músculos: Provas e Funções. 4 ed., São Paulo: Manole, 1995.
KNOPLICH, J. A coluna Vertebral: da Criança e do Adolescente. Santa Cecília: Panamed, 1985.

KNOPLICH, J. Viva Bem com a Coluna que Você Tem. 25ed., São Paulo: Ibrasa, 1996.

LAPIERRE, A. A Reeducação Física, vol. I, 6ed, São Paulo: Manole, 1982.

LE CAMUS, J. O Corpo em Discussão: da Reeducação Psicomotora às Terapias de Mediação Corporal. Porto Alegre: Artes Médicas, 1986.

METZLER, A.M.; CARPENA, L.B. \& BORGES, R.M.R. Fenomenologia como Filosofia e como Método de Investigação em Pesquisas Educacionais. In: ENGERS, E. A. (org.). Paradigmas e Metodologias de Pesquisa em Educação. Porto Alegre: EDIPUCRS, pp.7583, 1994.

MÜLLER, E. Du Spürst under deinen Füssen das Gras. Frankfurt am Main: Ficher, 1994.

RASCH, P.J. \& BURKE, R.K. Cinesiologia e Anatonia Aplicada: A Ciência do Movimento Humano. 5ed., Rio de Janeiro: Guanabara Koogan. 1977.

SCHILDER, P. A Imagem do corpo: As Energias Construtivas da Psique. 2ed., São Paulo: Martins Fontes, 1994.

SMITH, L.K.; WEISS, E.L. \& LEHMKUHL, L.D. Cinesiologia Clínica de Brunnstrom. 5ed., São Paulo: Manole, 1997.

SOUSA, A.V. Gimnasia Correctiva. 2ed., Barcelona: Sintes, 1972.

SOUZA, J.L. Untersuchungen zur Wirksamkeit von Bewegungsprogrammen bei Rückenbeschwerden. Inauguraldissertation zur Erlangung des Doktorgrades an der Fakultät für Sozial und Verhaltenswissenschaften der Ruprecht-KarlsUniversität Heidelberg, 1995.

VIEIRA, A. A corporeidade na Escola Postural. Dissertação de Mestrado. Universidade Federal do Rio Grande do Sul, 1998.

VIGARELLO, Le Corps Redressé: Histoire d'un Pouvoir Pédagogique. Paris: Jean-Pierre Delarge, 1978. 
* Adriane Vieira: Mestre em Ciências do Movimento Humano pela ESEF/UFRGS.

E-mail: adrianevieira@uol.com.br

** Jorge Luiz de Souza: Doutor em Prevenção e Reabilitaçã Esportiva pela Universidade de Heideiberg, Alemanha. E-

mail: jlsouza@ufrgs.com.br

Recebido em: 11.12.01

Revisado em: 26.03.02

Aceito em: 11.04.02 